Ciência Florestal, Santa Maria, v. 25, n. 1, p. 77-89, jan.-mar., 2015

ISSN 0103-9954

\title{
VARIAÇÃO DA ESTRUTURA DA FLORESTA ESTACIONAL DECIDUAL NO ESTADO DE SANTA CATARINA E SUA RELAÇÃO COM A ALTITUDE E CLIMA
}

\author{
STRUCTURAL VARIATION OF SEASONAL DECIDUOUS FOREST IN SANTA CATARINA STATE \\ AND ITS RELATIONSHIP WITH ALTITUDE AND CLIMATE
}

André Luís de Gasper ${ }^{1}$ Alexandre Uhlmann² Alexander Christian Vibrans $^{3} \quad$ Lucia Sevegnani $^{4}$

\section{RESUMO}

O objetivo deste trabalho foi identificar as possíveis similaridades estruturais entre remanescentes da Floresta Estacional Decidual (FED) em Santa Catarina e associar os grupos à influência de condicionantes ambientais. Associado a este objetivo primário, também se buscou a identificação das zonas de contato entre esta tipologia florestal e a Floresta Ombrófila Mista (FOM). Foram analisados os dados de 78 unidades amostrais (UA) instaladas em remanescentes da FED entre 2008 e 2009 pelo Inventário Florístico Florestal de Santa Catarina (IFFSC). Os dados foram tratados através da Análise de Correspondência Corrigida (DCA) e da Análise de Correspondência Canônica (ACC), valendo-se de uma matriz de densidade de espécies e uma matriz de variáveis ambientais, esta constituída por altitude e parâmetros climáticos. A proporção da variância explicada pelos três primeiros eixos da DCA foi baixa, somando aproximadamente $21 \%$ do total de informação contida no conjunto original de dados. Este resultado ofereceu baixo poder de interpretação para os resultados. No entanto, quando a DCA foi aplicada sobre os dados de densidade média das espécies em cada bacia hidrográfica, os resultados apontaram para autovetores muito explicativos do conjunto $(58,1 \%$ da variação). Observada somente a ordenação provocada pelo primeiro eixo da DCA, vêse a disposição das bacias de leste, em um extremo, e das bacias de oeste, no outro extremo deste eixo. Na extremidade direita do primeiro eixo estão dispostas as bacias do rio Canoas, Pelotas e do Peixe, as quais são caracterizadas pela presença de espécies como Ocotea pulchella, Zanthoxylum fagara, Lithrea brasiliensis, Matayba elaeagnoides, Cinnamodendron dinisii, comumente associadas com a Floresta Ombrófila Mista. $\mathrm{Na}$ extremidade esquerda estão distribuídas as bacias de oeste, grupo que inclui as bacias dos rios Jacutinga, Irani, Chapecó, Antas e Peperi-Guaçu. Dentre as espécies que mais fortemente influenciaram os resultados na análise, cabe destacar Apuleia leiocarpa, Rauvolfia sellowii, Bastardiopsis densiflora, Chrysophyllum gonocarpum, Cordia trichotoma, Holocalyx balansae, Myrocarpus frondosus e Pisonia zapallo, as quais são frequentes em florestas estacionais do interior meridional do Brasil. A análise através da ACC apontou para resultados similares e a interpretação conjunta dos dados ambientais indicou que as UA situadas nas bacias de leste estão associadas a climas mais frios, em que as geadas são mais frequentes, como consequência de altitudes mais elevadas. Considerando que as altitudes tendem a declinar das porções lestes para oeste e, diante do resultados apresentados, os autores propõem a existência de uma zona de transição entre as duas regiões fitoecológicas (FOM e FED) na faixa dos 600 m s.n.m., onde ocorre a interdigitação de elementos da flora estacional e aqueles da Floresta Ombrófila Mista, resultando na delimitação de uma área core da FED abaixo deste patamar altimétrico.

Palavras-chave: análise multivariada; mata atlântica; ecótonos florestais.

1 Biólogo, Msc., Professor do Departamento de Ciências Naturais, Universidade Regional de Blumenau, Herbário Dr. Roberto Miguel Klein, Rua Antônio da Veiga, 140, Victor Konder, CEP 89012-900, Blumenau (SC), Brasil. algasper@gmail.com

2 Biólogo, Dr., Pesquisador da Embrapa Florestas, Estrada da Ribeira, Km 111, Caixa Postal 319, CEP 83411-000, Colombo (PR), Brasil. alexandre@cnpf.embrapa.br

3 Engenheiro Florestal, Dr., Professor do Departamento de Engenharia Florestal, Universidade Regional de Blumenau, Rua São Paulo, 3250, CEP 89030-000, Blumenau (SC), Brasil. acv@furb.br

4 Bióloga, Dr ${ }^{\mathrm{a}}$., Professora do Departamento de Ciências Naturais, Universidade Regional de Blumenau, Herbário Dr. Roberto Miguel Klein, Rua Antônio da Veiga, 140, Victor Konder, CEP 89012-900, Blumenau (SC), Brasil. sevegn@furb.br 


\begin{abstract}
This study aims to identify structural similarities between the remnants of seasonal deciduous forest (SDF) in Santa Catarina state and check the influence of environmental factors that leads the formation of these groups. Associated with this primary objective, it was also sought to identify the areas of contact between this forest type and Araucaria forest (mixed ombrophilous forest - MOF). We analyzed data from 78 sample units (AU) installed in the remnants of SDF between 2008 and 2009 by professional team of Floristic and Forest Inventory of Santa Catarina project (IFFSC). The data were processed through the Detrended Correspondence Analysis (DCA) and Canonical Correspondence Analysis (CCA), using a matrix of species density associated with a environmental variables matrix, that consisted of altitude and climate parameters. The proportion of variance explained by the first three axes of DCA was low, accounting for approximately $21 \%$ of the information contained in the original data set. This result provides low power of interpretation of the results. However, when DCA was applied to the data of mean density of species in each river basin, the results pointed to better explanatory eigenvectors (three first eigenvectors explain $58.1 \%$ of total variance). The first ordination axis of DCA grouped the eastern watersheds SUs at one end, and the western watersheds SUs at the other end of this axis. At the right end of the first axis are arranged the watersheds of the river Canoas, Pelotas and Peixe, which are characterized by the presence of species such as Ocotea pulchella, Zanthoxylum fagara, Lithrea brasiliensis, Matayba elaeagnoides, Cinnamodendron dinisii commonly associated with Mixed Ombrophilous Forest (Araucaria forest). At the left end, the grouped SUs are mainly those of western watersheds, a group that includes the basins of the Jacutinga, Irani, Chapecó, Antas and Peperi-guaçu rivers. Among the species that most strongly influence the results in the analysis, we highlight Apuleia leiocarpa, Rauvolfia sellowii, Bastardiopsis densiflora, Chrysophyllum gonocarpum, Cordia trichotoma, Holocalyx balansae, Myrocarpus frondosus and Pisonia zapallo, which are common in seasonal forests of the hinterlands of southern Brazil. The analysis through the ACC pointed to similar results and joint interpretation of environmental data indicated that the basins located in the east are associated with colder climates where frosts are more frequent as a result of higher altitudes. As the altitudes tend to decline from east to west and portions, the authors propose the existence of a transition zone between the two phytoecological regions (MOF and SDF) in the range of $600 \mathrm{~m}$ asl, where occurs the interdigitation of elements from seasonal flora and those of Araucaria forest, resulting in the delineation of a core area of the SDF below this altitudinal level.
\end{abstract}

Keywords: multivariate analysis; Atlantic forest; forest ecotones.

\section{INTRODUÇÃO}

Florestas estacionais são caracterizadas por atributos estruturais relacionados com a caducifolia condicionada por estacionalidade climática de temperatura e/ou precipitação. Baseado nestes atributos, o sistema de classificação da vegetação brasileira reconhece duas tipologias, a floresta estacional semidecídua e a floresta estacional decídua, as quais estão distribuídas principalmente no interior do Brasil, vinculadas essencialmente aos Biomas Mata Atlântica e Cerrado (VELOSO et al., 1991).

No âmbito do Bioma Mata Atlântica, as florestas estacionais distribuem-se principalmente nas regiões interiores, longe da margem oceânica dominada pela Floresta Ombrófila Densa (OLIVEIRA-FILHO e FONTES,
2000). Sua distribuição, aparentemente, segue padrões fortemente vinculados aos esquemas de precipitação e temperatura (OLIVEIRA-FILHO e FONTES, 2000) e secundariamente a isso, fatores como geologia e geomorfologia que influenciam a distribuição dos canais de drenagem, bem como as características pedológicas (OLIVEIRA-FILHO e RATTER, 2002; GIEHL e JARENKOW, 2008).

É caracterizada biogeograficamente pela contribuição de um contingente florístico mesossulamericano, oriundo da conhecida "rota seca", compreendida pelas bacias do Paraná e Uruguai (IBGE, 1991; PRADO e GIBBS, 1993; JARENKOW e WAECHTER, 2001). Segundo uma das hipóteses que explica o surgimento de sua flora, durante o último máximo glacial, com a queda dos níveis de precipitação e das temperaturas, as florestas teriam ficado reclusas a espaços mais 
úmidos. Com o ingresso de umidade e aumento das temperaturas durante o Holoceno, seria esperada a expansão destas florestas para além de seus limites antigos, formando uma arco iniciado no núcleo Caatinga, no nordeste brasileiro, passando através das bacias do Paraná/Uruguai/Paraguai, até as florestas Tucumano-bolivianas (PRADO e GIBBS, 1993).

Dada a amplitude de sua distribuição, a biota das florestas tropicais estacionais deve ter experimentado distintas histórias naturais e biogeografias, fato evidenciado pela presença de poucas espécies de ampla distribuição espacial no Neotrópico (PENNINGTON et al., 2009).

Em Santa Catarina, esta floresta expressa a deciduidade das folhas no período entre maio e setembro, como resultado de fatores climáticos restritivos, como o frio e o menor fotoperíodo do semestre de inverno. A deciduidade segundo Klein (1972, 1978) e IBGE (1991) ocorre especialmente nas plantas do dossel e emergentes, atingindo valores superiores a $50 \%$ das espécies componentes, o que levou os proponentes do sistema de classificação da vegetação brasileira a enquadrá-la como uma floresta estacional decídua (VELOSO et al., 1991). Neste estado, sua área original ocupava 7.967 $\mathrm{km}^{2}$ distribuídos em parte da bacia hidrográfica do rio Uruguai, incluindo as porções médias e baixas dos seus tributários rios Pelotas, Canoas, do Peixe, Jacutinga, Irani, Chapecó, Antas e PeperiGuaçu (KLEIN, 1978). A flora frequentemente associada à FED inclui espécies como a peroba-rosa (Aspidosperma polyneuron Müll. Arg.), o ipê-roxo (Handroanthus heptaphyllus (Vell.) Mattos), o paud'alho (Gallesia integrifolia (Spreng.) Harms), o pau-marfim (Balfourodendron riedelianum (Engl.) Engl.), a canafístula (Peltophorum dubium (Spreng.) Taub.), o louro-pardo (Cordia trichotoma (Vell.) Arráb. ex Steud.) e a grápia (Apuleia leiocarpa (Vogel) J.F. Macbr.) (LEITE, 1994).

Esta representa uma vegetação recente em Santa Catarina (BIGARELLA, 1964), com seu ingresso posterior àquele dos campos e da Floresta Ombrófila Mista, sendo considerada um prolongamento das florestas da bacia do rio Paraná e migrações da província de Missiones (RAMBO, 1951; 1956; SPICHIGER et al., 2004; PENNINGTO Net al., 2009). Spichiger et al. (2004) ressaltaram o papel dos corredores formados pelos canais fluviais da bacia do Paraná na difusão de elementos bióticos, conforme pode ser deduzido através da visualização dos mapas de vegetação dos estados do Paraná,
Santa Catarina e Rio Grande do Sul (KLEIN, 1978; MAACK, 1947; 1968 e RAMBO, 1951). Como consequência desta possível expansão, zonas de contato com a Floresta Ombrófila Mista (floresta com araucária) e com a Estepe (campos naturais) são formadas em Santa Catarina recebendo contribuições florísticas destas. No Paraná, ao longo do vale do rio Tibagi,Torezan (2002) descreveu a ocorrência de uma zona de contato entre a Floresta Estacional e a Floresta Mista estabelecida em uma faixa de altimétrica situada entre 500 e $800 \mathrm{~m}$.

Apesar de ser uma tipologia florestal importante sob o ponto de vista biológico, Pennington et al. (2000) ressaltaram que estas florestas estariam recebendo pouca atenção da sociedade, tanto no que diz respeito aos esforços de conservação, quanto por parte de pesquisas visando à compreensão dos padrões disjuntos de sua distribuição no Neotrópico. Nos três estados da região Sul do Brasil, as florestas estacionais possuem destaque, pois sua distribuição original está vinculada à região de grande desenvolvimento agrícola e pecuário. No estado de Santa Catarina, poucos são os trabalhos que abordam as florestas estacionais, contrastando com aqueles produzidos no Rio Grande do Sul, conforme atesta a recente síntese feita por Schumacker et al. (2011), somando-se a este, alguns outros autores que trataram de aspectos florísticos (SCIPIONI et al., 2011), fitossociológicos (KILCA e LONGHI 2011) e fenológicos (ALBERTI et al., 2011). Além destes, Ferraz e Roberti (2011) e Pedron e Dalmolin (2011) detiveram-se na análise de fatores ecológicos importantes, como o clima e o solo.

Diante desta carência de dados, este trabalho pretende contribuir com a exposição de novos conhecimentos sobre a floresta estacional do estado de Santa Catarina, baseando-se nos dados de um extensivo levantamento feito através do Inventário Florístico Florestal de Santa Catarina (IFFSC). Deseja-se provar que existem variações expressivas na estrutura das florestas estacionais catarinenses e que estas são o resultado de variações de caráter ambiental, principalmente relacionadas com o clima (em última análise, ligadas à variação altimétrica). Um segundo aspecto que constitui objetivo deste trabalho é provar a ocorrência de uma zona de transição no contato entre a Floresta Ombrófila Mista e a floresta estacional decídua.

\section{MATERIAL E MÉTODOS}

A área de estudo inclui parte das bacias 
dos afluentes do rio Uruguai em Santa Catarina (Figura 1) e que foi incluída por Klein (1978) na região fitoecológica da FED. As Unidades Amostrais (UA) foram distribuídas de forma sistemática em uma uma grade de pontos com distância de $5 \times 5 \mathrm{~km}$ em coordenadas UTM (Datum WGS 84), seguindo os procedimentos preconizados pelo IFFSC (VIBRANS et al., 2010). A identificação destes fragmentos foi feita através de imagens Landsat-5 TM de 2003, e SPOT-4 e SPOT-5 de 2005 (VIBRANS et al., 2010), a fim de conferir a existência de floresta antes das equipes se deslocarem ao campo.

O método de amostragem foi o de área fixa e as UA foram alocadas em conglomerados. Cada conglomerado, em formato de cruz, possuía quatro subunidades de $20 \times 50 \mathrm{~m}$ cada, orientadas na direção dos quatro pontos cardeais (norte, sul, leste e oeste), mantendo cada uma, $30 \mathrm{~m}$ de distância do centro do conglomerado. Este formato conferiu ao conglomerado uma área amostral de $4.000 \mathrm{~m}$ e uma área de inclusão de 2,56 hectares (VIBRANS et al., 2011). Todos os indivíduos com DAP $\geq 10 \mathrm{~cm}$ foram mensurados.

Os dados das 78 UA foram utilizados para a construção de uma matriz de densidades das espécies nelas encontradas. Nesta matriz, as linhas representaram as espécies e as colunas, as unidades amostrais (UA), sendo cada célula preenchida pelo valor da densidade absoluta (número de indivíduos por hectare) das $i$ espécies em cada $n$ Unidade Amostral.

Antes da construção da matriz de densidade, do total de 232 espécies amostradas nas 78 unidades amostrais, foram eliminadas aquelas consideradas raras, mortas e a categoria das não identificadas, restando 79 espécies. Foram consideradas raras, neste trabalho, aquelas que apresentaram valor médio de densidade inferior a um indivíduo por hectare. Este valor médio de densidade da espécie (VMDi) foi calculado de acordo com a fórmula abaixo:

$$
V M D_{n}=\frac{\sum_{i}^{n} D A_{i}}{N T U A}
$$

Em que: $\mathrm{DA} i=$ densidade absoluta da espécie $i$ na unidade amostral $p$; NTUA = número total de unidades amostrais no levantamento.

A eliminação das espécies raras foi realizada porque estas podem diminuir o poder de ordenação

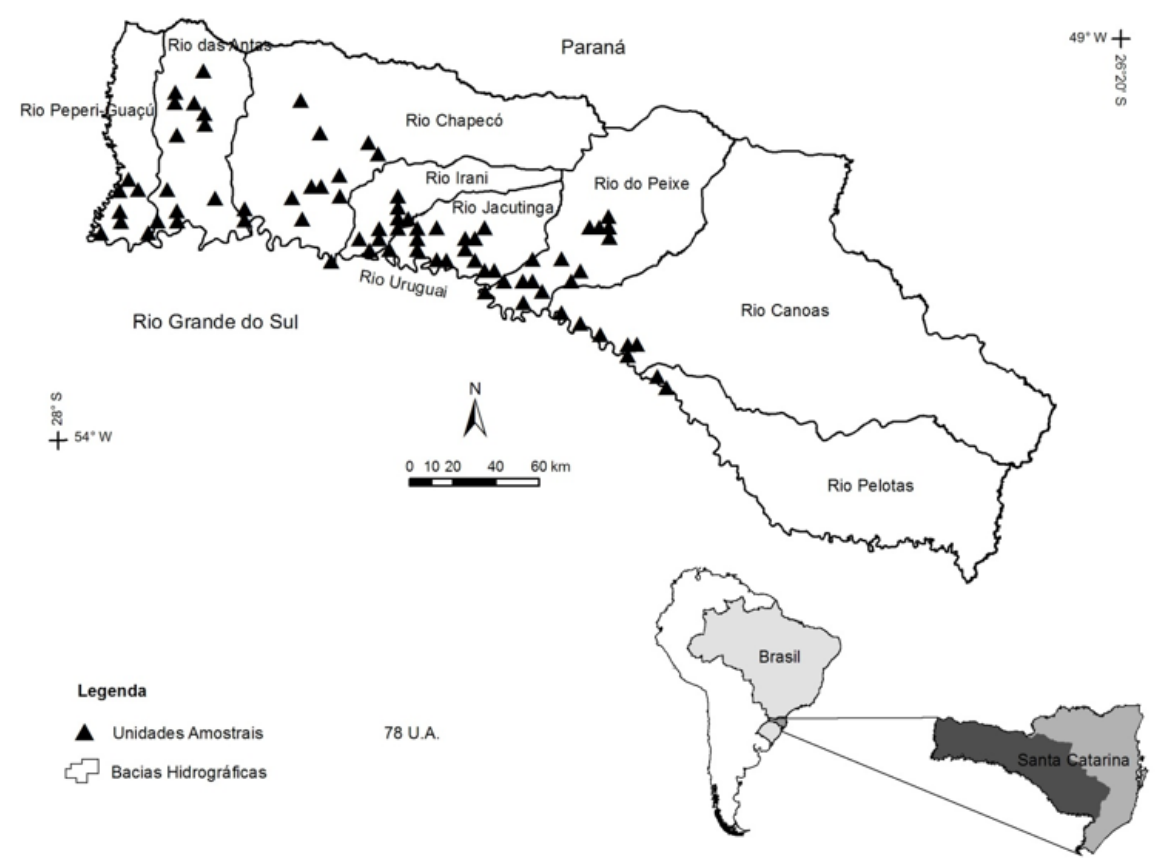

FIGURA 1: Área de distribuição da Floresta Estacional Decidual no oeste de Santa Catarina e as unidades amostrais (UA) localizadas nas bacias hidrográficas dos tributários de margem direita do rio Uruguai.

FIGURE 1: Distribution of Seasonal Deciduous Forest in western of Santa Catarina state and the sampling units $(\mathrm{SU})$ in the right sided watersheds of Uruguay river's tributaries. 
dos dados. Segundo Gauch-Junior (1982), as espécies com poucos indivíduos amostrados não influenciam na formação dos agrupamentos.

Comisso, originou-seuma matrizconstituída por 79 espécies (linhas) e 78 UA (colunas) a qual foi submetida à Análise de Correspondência Corrigida (Detrended Correspondence Analisys - DCA). A análise de correspondência foi escolhida para uma inspeção inicial dos resultados e teve por objetivo encontrar grupamentos de UA cujas características estruturais (no caso, relacionadas com a densidade das espécies amostradas) fossem aproximadas. Como este método permite plotar os escores das UA e também os das espécies associadas aos grupamentos, mostrou-se valioso para interpretar os resultados sinoticamente. $\mathrm{O}$ valor da variância extraída através de cada um dos autovetores foi obtido através dos autovalores $(\lambda n)$ associados. A análise gráfica dos autovetores projetados em um plano cartesiano permitiu a visualização da ordenação das unidades amostrais e das espécies.

A mesma análise (DCA) foi aplicada aos dados da matriz de bacias hidrográficas (rios Canoas, Pelotas, Peixe, Jacutinga, Irani, Chapecó, Antas e Peperi-Guaçu). Como a matriz original continha o valor da densidade em cada UA, foi necessário obter a média da densidade de cada espécie em cada uma das bacias hidrográficas. Com esta operação, obteve-se o número médio de indivíduos da espécie $i$ em cada uma das bacias hidrográficas. A matriz gerada, sobre a qual foi aplicada a Análise de Correspondência, foi então constituída por 79 linhas (espécies) e oito colunas (bacias hidrográficas), sendo as células correspondentes ao número médio de indivíduos por hectare de cada espécie em cada bacia hidrográfica.

Com a finalidade de verificar as relações entre as UA e fatores ambientais, foi conduzida a Análise de Correspondência Canônica (ACC). A mesma matriz utilizada na DCA foi aqui empregada, mas como a ACC requer uma segunda matriz que contenha as variáveis ambientais, esta foi gerada com base no Atlas Climatológico de Santa Catarina (EPAGRI, 2008). Os dados desta foram obtidos através da sobreposição das UA no arquivo shape do atlas, tornando possível extrair as informações necessárias. Entretanto, antes de os dados serem analisados, a matriz de dados ambientais foi submetida a uma Análise de Componentes Principais (PCA) a fim de selecionar aquelas variáveis multicolineares e reduzir a redundância da análise. Desta forma, foram mantidas na análise as seguintes variáveis: altitude (como variável geográfica), temperatura média, precipitação, dias de geada e umidade (como variáveis climáticas). Permutações Monte Carlo ( $\mathrm{n}=999$ ) foram feitas a fim de testar a significância das correlações obtidas. $\mathrm{O}$ processamento dos dados e as análises foram feitas com auxílio dos softwares Mata Nativa 2 (CIENTEC, 2002), Microsoft Office Excel (2007) e CANOCO for Windows 4.5 (TER BRAAK e SMILAUER, 2002).

\section{RESULTADOS E DISCUSSÃO}

\section{A aplicação da Análise de} Correspondência Corrigida (DCA) à matriz constituída pelos dados de densidade das espécies em cada unidade amostral (UA) apontou para resultados pouco conclusivos. Isto porque os três primeiros eixos da DCA resultaram na agregação de somente $21 \%$ da variância original dos dados (DCA1 $=9,3 \%$; DCA2 $=7,3 \%$; DCA3 = 4,4\%). Mesmo que fosse agregado um número maior de dimensões, como a proporção da variância capturada em cada um dos vetores foi muito pequena, seria necessário somar um grande número destes, o que tornaria a avaliação dos resultados pouco prática. É possível, portanto, que isto seja o resultado da atuação de diversos fatores na determinação da distribuição das espécies, tornando difícil a interpretação da ordenação.

Por outro lado, a mesma análise aplicada à matriz constituída pelos dados de densidade média das espécies em cada uma das bacias mostrou resultados satisfatórios. Os três primeiros autovalores explicaram $58,1 \%$ da variância original dos dados $($ DCA $1=42,2 \%$; DCA2 $=9,7 \%$; DCA3 $=6,2 \%)$. A Figura 2 , na qual estão apresentados os resultados da DCA, permite observar a tendência de separação das bacias situadas mais a leste (à direita na Figura) daquelas situadas mais a oeste (à esquerda na Figura).

A ordenação permitiu identificar as espécies que caracterizam os dois grupos de bacias hidrográficas. As espécies associadas ao grupo de bacias hidrográficas do oeste foram: Aloysia virgata (Ruiz \& Pav.) Juss., Apuleia leiocarpa (Vogel) J.F. Macbr., Bastardiopsis densiflora (Hook. \& Arn.) Hassl., Campomanesia xanthocarpa (Mart.) O. Berg, Casearia sylvestris Sw., Chrysophyllum gonocarpum (Mart. \& Eichler ex Miq.) Engl., Cordia trichotoma (Vell.) Arráb. ex Steud., Cyathea corcovadensis (Raddi) Domin, Ficus luschnathiana 


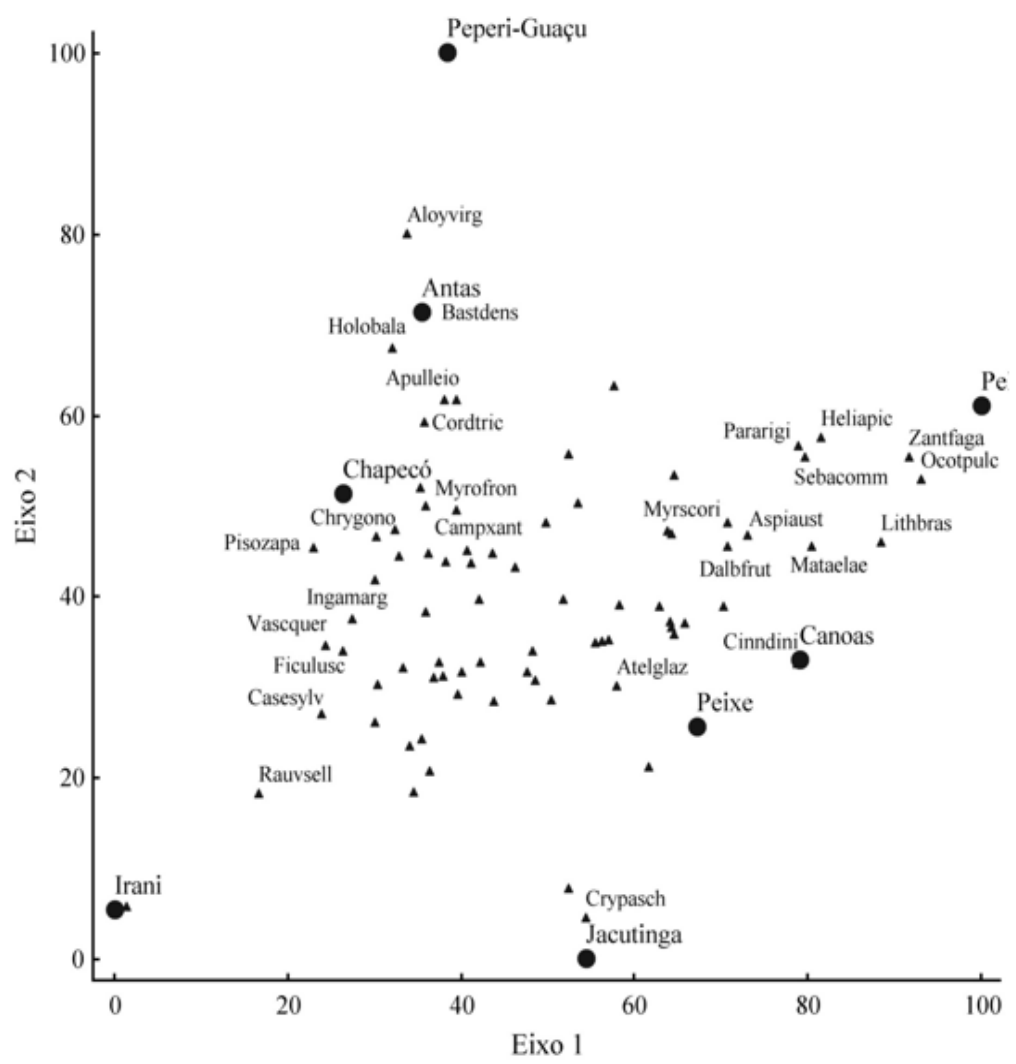

FIGURA 2: Ordenação obtida através da aplicação de DCA em uma matriz de dados de densidade média das espécies em cada bacia hidrográfica na área de abrangência da floresta estacional decidual do estado de Santa Catarina.

FIGURE 2: Ordination yielded from DCA applied on a matrix composed by mean density of species surveyed in each hydrographic basin located at the range of seasonal deciduous forest of Santa Catarina State, Brazil.

(Miq.) Miq., Holocalyx balansae Micheli, Inga marginata Willd., Myrocarpus frondosus Allemão, Pisonia zapallo Griseb., Rauvolfia sellowii Müll. Arg. e Vasconcellea quercifolia A.St.-Hil.

Com relação às bacias hidrográficas do leste, as espécies que influenciaram sua separação foram: Ocotea pulchella (Nees \& Mart.) Mez, Zanthoxylum fagara (L.) Sarg., Lithrea brasiliensis Marchand, Helietta apiculata Benth., Matayba elaeagnoides Radlk., Sebastiania commersoniana (Baill.) L.B. Sm. \& Downs, Parapiptadenia rigida (Benth.) Brenan, Dalbergia frutescens (Vell.) Britton, Cinnamodendron dinisii Schwacke, Aspidosperma australe Müll. Arg., Myrsine coriacea (Sw.) R. Br. ex Roem. \& Schult, Ateleia glazioveana Baill. e Cryptocarya aschersoniana Mez.

Dentre aquelas espécie citadas anteriormente e que se encontram fortemente vinculadas às bacias de oeste, pode-se destacar que Rauvolfia sellowii, Chrysophyllum gonocarpum, Holocalyx balansae e Apuleia leiocarpa parecem estar mais fortemente associadas à FED ou, no caso do Paraná, à Floresta Estacional Semidecidual (MARKGRAF, 1968; REITZ, 1968; REITZ et al., 1978; REITZ et al., 1988; INOUE et al., 1984), embora as duas últimas tenham sua ocorrência associada com a FOM também. Cordia trichotoma e Myrocarpus frondosus Allemão são espécies que se distribuem tanto pela FED ou FES, quanto pela FOM, mas a primeira delas parece ter preferência pelas florestas estacionais (INOUE et al., 1984; REITZ, 1974; REITZ et al., 1978; REITZ et al., 1988; SMITH, 1970) e Pisonia zapallo é característica da Floresta Ombrófila Densa e das florestas estacionais dos rios Paraná e do Uruguai, sendo na FED seus valores sociológicos pouco expressivos (REITZ, 1970). Ateleia glazioveana ocorre em matas secundárias e orla da mata na bacia do Alto Uruguai (REITZ et al., 1988). Da mesma forma, Bastardiopsis 
densiflora ocorre no alto Uruguai, mas de acordo com Reitz et al., (1988), esta ocorre de forma descontinua. Campomanesia xanthocarpa ocorre preferencialmente na FOM, em solos úmidos (REITZ et al., 1988), mas neste trabalho, encontrase associada ao grupo de bacias de oeste. Casearia sylvestris é uma espécie distribuída por todo o estado de Santa Catarina, desde o litoral até a FED, mas preferencialmente na Floresta Ombrófila Densa (KLEIN; SLEUMER, 1984). Inga marginata prefere ambientes mais úmidos, próximos a rios e regatos (REITZ et al., 1988), bem como Sebastiania commersoniana, espécie caducifólia e distribuída por todo o estado (REITZ et al., 1988). Cyathea corcovadensis ocorre em áreas mais drenadas e secas (VELOSO; KLEIN 1959). Cryptocarya aschersoniana, ocorre em todo o estado de Santa Catarina, mas estaria mais associada à FOM (REITZ et al., 1988).

Segundo Klein (1972), Apuleia leiocarpa, Parapiptadenia rigida (Benth.) Brenan, Cordia trichotoma, Cordia americana (L.) Gottschling \& J.S. Mill., Diatenopterix sorbifolia Radlk., Lonchocarpus leucanthus Burkart, Cabralea canjerana (Vell.) Mart., Peltophorum dubium (Spreng.) Taub., Cedrela fissilis Vell., Balfourodendron riedelianum (Engl.) Engl. e Enterolobium contortisiliquum (Vell.) Morong constituem-se nas espécies mais importantes da floresta estacional de Santa Catarina. Por vezes Myrocarpus frondosus se torna bastante comum. Três destas espécies citadas pelo autor (Apuleia leiocarpa, Cordia trichotoma e Myrocarpus frondosus) são responsáveis pela delimitação dos grupos de bacias de oeste.

As mesmas espécies são citadas como importantes para a caracterização da FOM do extremo oeste catarinense (KLEIN, 1978), dentre outras como: Araucaria angustifolia, Parapiptadenia rigida, Cordia americana, Diatenopteryx sorbifolia, Lonchocarpus leucanthus, Nectandra lanceolata Nees, Nectandra megapotamica (Spreng.) Mez, Ocotea puberula (Rich.) Nees, Cedrela fissilis, Phytolacca dioica L., Peltophorum dubium, Balfourodendron riedelianum e Myrocarpus frondosus. Estas espécies dão caráter transicional para a FOM nesta região geográfica, porque são consideradas como características da FED, exceto por Araucaria angustifolia.

Por outro lado, Matayba elaeagnoides, Cupania vernalis, Myrcia guianensis (Aubl.) DC., Cinnamodendron dinisii, Campomanesia xanthocarpa, Lamanonia ternata Vell., Quillaja brasiliensis (A.St.-Hil. \& Tul.) Mart., Clethra scabra Pers., Prunus myrtifolia (L.) Urb., Myrcianthes gigantea (D. Legrand) D. Legrand, Ilex theezans Mart. ex Reissek e Luehea divaricata Mart. \& Zucc. são espécies que caracterizam, segundo Klein (1978), a FOM das bacias do alto Canoas e Pelotas. Sobre Aloysia virgata e Vasconcellea quercifolia não foram encontrados dados para esta discussão.

O que se observa a partir destas comparações feitas com a literatura, é que, de um modo geral, as bacias de leste incluem UA que caracterizam tipos intermediários entre a floresta estacional decidual e a Floresta Ombrófila Mista. Por outro lado, as bacias de oeste incluem um grande número de espécies características da flora das florestas estacionais.

Os dados também foram tratados através da Análise de Correspondência Canônica (ACC) e parte dos seus resultados está sumarizada na Tabela 1. Sem considerar as variáveis ambientais, o

TABELA 1: Síntese dos resultados da Análise de Correspondência Canônica (ACC) aplicada às matrizes de dados de densidade das espécies e dados ambientais das 78 UA da Floresta Estacional Decidual.

TABLE 1: Results of canonical correspondence analyses (CCA) applied to data matrixes of species density and environmental variables of 78 SU of the Seasonal Deciduous Forest.

\begin{tabular}{lccc}
\hline \multicolumn{1}{c}{ Eixos } & CCA 1 & CCA 2 & CCA 3 \\
\hline Autovalores & 0,157 & 0,092 & 0,077 \\
Correlação de Pearson para espécies/dados ambientais & 0,763 & 0,623 & 0,705 \\
\hline \multicolumn{1}{c}{ Percentagem da variação cumulativa } & & & \\
\hline das espécies & 3,7 & 5,8 & 7,6 \\
dos dados ambientais & 38,0 & 60,3 & 78,9 \\
\hline Grau de significância (Teste de Monte Carlo) & 0,001 & & \\
\hline
\end{tabular}


primeiro eixo da ACC explica 3,7\% da variância dos dados. As variáveis ambientais sozinhas explicam 9,6\% dos dados apresentados, destes 38,0\% estão no primeiro eixo da ACC (Tabela 1). Observa-se através da Correlação Linear de Pearson que as variáveis ambientais, sozinhas, não são a principal explicação para a variação dos dados $(\mathrm{p}>0,05)$.

A Tabela 2 aponta as variáveis ambientais que mais fortemente se correlacionam com os eixos da ACC. O primeiro eixo canônico possui elevada correlação positiva com os dados de altitude e dias de geada (valores com * na Tabela 2), da mesma forma como aponta para uma relação inversa com a temperatura média. Isto parece indicar que a estrutura da vegetação está atrelada ao gradiente altitudinal que, por sua vez, condiciona as variações de temperatura média e de ocorrência de geadas. A Floresta Estacional Decidual, em Santa Catarina, está situada entre cotas altimétricas que vão desde 250 até 900 metros. As zonas mais baixas estão localizadas nas proximidades da calha do rio Uruguai, enquanto as de maior elevação encontramse nas zonas dos vales médios de seus principais afluentes.

De fato, a altitude média das UA inseridas nas bacias dos rios Canoas e Pelotas foi de 757 e $691 \mathrm{~m}$, respectivamente. Embora estas médias não estejam distantes daquelas verificadas para as UA localizadas na bacia do rio do Peixe $(663 \mathrm{~m})$ e do rio Irani $(640 \mathrm{~m})$, esta média vai diminuindo gradativamente na direção das bacias de oeste (Tabela 3), podendo assim levar à compreensão das razões que aproximam estruturalmente as florestas localizadas naquelas bacias com a Floresta Ombrófila Mista. No mapa de vegetação do estado de Santa Catarina (KLEIN, 1978), vê-se esta segregação associada com a distribuição da Floresta Ombrófila Mista (FOM) a leste e a norte, nas porções mais elevadas, assim como da Floresta Estacional Decidual (FED), nas porções de menor altitude do estado, proximamente ao vale do rio Uruguai.

De acordo com estes resultados e conforme observado na Figura 3 e na Tabela 3 , as UA localizadas em regiões em que se verificam geadas mais frequentes e temperaturas médias anuais mais baixas, estão situadas mais a leste, em áreas mais elevadas, em sua maioria localizadas no âmbito das bacias dos rios Pelotas, Canoas e do Peixe, as quais quase sempre se encontram associadas com elementos florísticos da Floresta Ombrófila Mista, conforme já discutido anteriormente, quando apresentados os resultados da análise de correspondência corrigida (DCA).

Por outro lado, as correlações do segundo eixo da ACC, positiva com as precipitações médias e negativa com a média da umidade relativa do ar (Tabela 2), indicam haver alguma influência destes dois fatores na ordenação dos dados. Nos quadrantes superiores do plano de cartesiano representado na Figura 3, vê-se que o conjunto de UA relacionadas com elevadas precipitações anuais é, na sua maioria, representado por aquelas contidas na bacia do rio das Antas. Ressalta-se, contudo, que apesar de a região possuir elevados índices pluviométricos, as precipitações não possuem regularidade, sendo mal distribuídas ao longo do ano (EPAGRI, 2008). Assim, apesar de a grande maioria das bacias de oeste inserir-se no conjunto daquelas que apontam para elevados índices pluviométricos (Tabela 2), parece ser esta também a região de mais forte estacionalidade de sua distribuição. Com respeito à umidade, a Figura 3 demonstra haver uma forte influência deste parâmetro na determinação da dissociação de algumas UA, mas principalmente daquelas situadas na bacia do Peperi-Guaçu. De fato, a Tabela 2 parece indicar que a média da umidade relativa do ar é superior àquela de todas as demais, exceto pela bacia do rio Pelotas, que se equivale a esta. Contudo, a pequena amplitude de variação deste dado (Tabela 3 ) torna difícil avaliar estes resultados.

A dissecação do relevo provocada pelo rio Uruguai, somado aos processos morfogenéticos que deram origem aos sistemas de patamares elevados (toda a área considerada inclui-se na bacia do Paraná, mais especificamente sobre os derrames basálticos da Formação Serra Geral, segundo Petri e Fúlfaro (1983); Mizusaki e Thomáz-Filho (2004) - ou ainda do derrame do Trapp - conforme denominou Maack (1947)), soerguidos por processos epirogenéticos, foram responsáveis pela conformação altimétrica e pela configuração das geoformas da área estudada. As flutuações climáticas pretéritas, as quais condicionaram processos de expansão e retração das tipias vegetacionais (BEHLING, 1997; BEHLING e NEGRELLE, 2001; BEHLING et al., 2005), certamente contribuíram para o estabelecimento de conexões florísticas que devem ser consideradas na avaliação destes resultados, tendo em vista a geração de zonas de contato entre diferentes tipias florestais. Maack (1968) considerou a possibilidade de retração da Floresta Ombrófila Mista, levando-a a ficar confinada a áreas de clima subtropical no estado do Paraná. Reitz e Klein, (1966) já haviam 


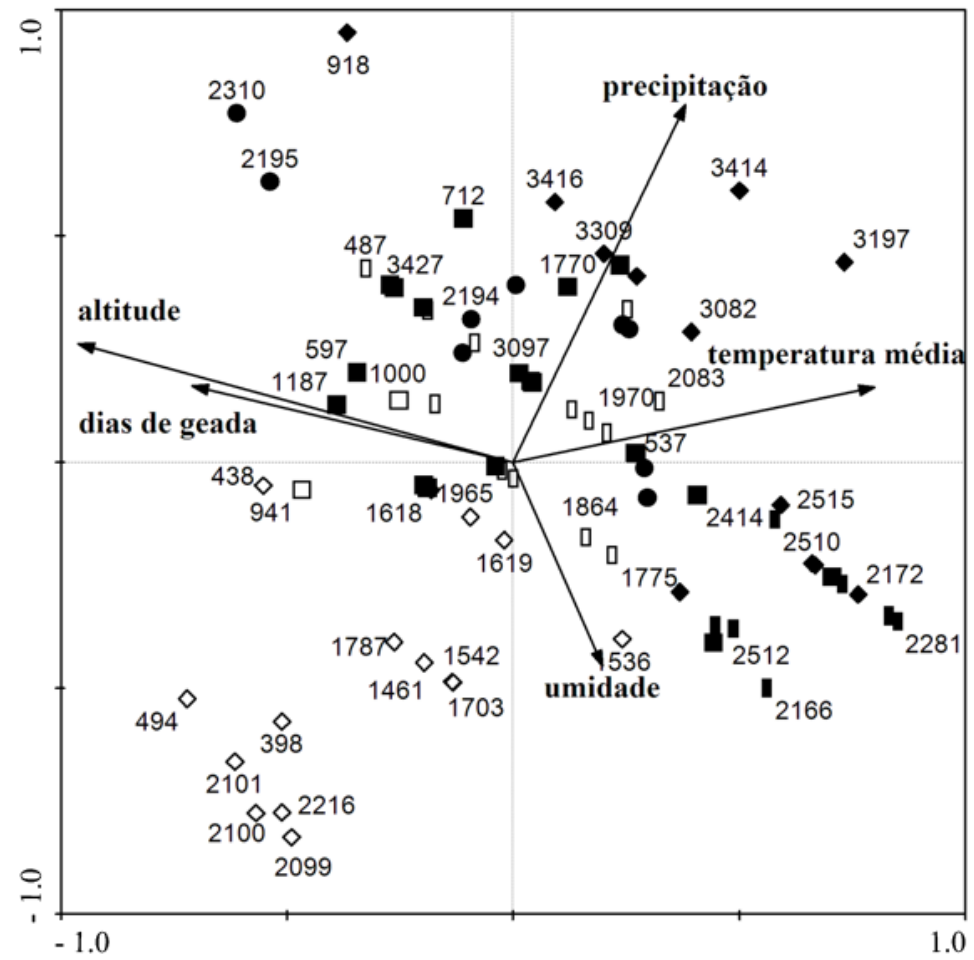

Legenda:

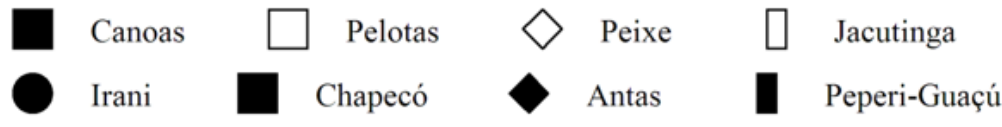

FIGURA 3: Resultados da ordenação obtida através da Análise de Correspondência Canônica aplicada às matrizes de dados ambientais e de densidade das espécies principais levantadas em 78 unidades amostrais da distribuídas nos remanescentes de floresta estacional decidual em Santa Catarina.

FIGURE 3: Ordination results yielded by Canonical Correspondence Analysis applied to environmental data and main species density surveyed in 78 sample units distributed in remnants of seasonal deciduous forest in Santa Catarina state.

TABELA 2: Coeficientes de correlação entre as variáveis ambientais e os eixos canônicos extraídos através da ACC aplicada às variáveis ambientais e matriz de densidade de espécies nas 78 unidades amostrais da Floresta Estacional Decidual em Santa Catarina.

TABLE 2: Correlation coefficients between environmental variables and canonical axes extracted by CCA applied upon environmental variables and species density matrixes of 78 sampled units of seasonal deciduous forest of Santa Catarina State.

\begin{tabular}{lccc}
\hline \multicolumn{1}{c}{ Parâmetros climáticos } & Eixo 1 & Eixo 2 & Eixo 3 \\
\hline Altitude & $0,734^{*}$ & 0,163 & 0,047 \\
Precipitação & $-0,291$ & $0,493^{*}$ & 0,071 \\
Temperatura média & $-0,610^{*}$ & 0,103 & 0,120 \\
Dias de geada & $0,541^{*}$ & 0,105 & $-0,377^{*}$ \\
Umidade relativa do ar & $-0,151$ & $-0,281^{*}$ & 0,300 \\
\hline
\end{tabular}

Em que: * Indicação de elevada correlação prática entre o eixo econômico com os dados de altitude e dia de geada. 
TABELA 3: Parâmetros ambientais médios das unidades amostrais (UA) em cada bacia hidrográfica considerada no presente estudo.

TABLE 3: Average environmental parameters of sample units (SU) in each hydrografic basin considered in this study.

\begin{tabular}{cccccc}
\hline Bacia hidrográfica & Altitude(m) & $\begin{array}{c}\text { Precipitação média } \\
\text { anual }(\mathrm{mm})\end{array}$ & $\begin{array}{c}\text { Temperatura } \\
\text { média anual }\left({ }^{\circ} \mathrm{C}\right)\end{array}$ & $\begin{array}{c}\text { Frequência média anual } \\
\text { de geadas (dias por ano) }\end{array}$ & $\begin{array}{c}\text { Umidade } \\
\text { Relativa do } \\
\text { ar (\%) }\end{array}$ \\
\hline Peperi-guaçu & 329 & 1.800 & 19,1 & 6,79 & 79,0 \\
Antas & 465 & 1.917 & 19,0 & 8,92 & 77,8 \\
Chapecó & 553 & 1.846 & 18,5 & 9,27 & 77,5 \\
Irani & 640 & 1.889 & 18,4 & 8,61 & 77,2 \\
Jacutinga & 603 & 1.829 & 18,5 & 9,21 & 77,9 \\
Peixe & 663 & 1.480 & 18,0 & 10,43 & 77,7 \\
Canoas & 691 & 1.733 & 18,3 & 9,50 & 77,3 \\
Pelotas & 757 & 1.800 & 18,0 & 9,50 & 79,0 \\
\hline
\end{tabular}

descrito que a zona das araucárias encontrava-se em recuo frente ao avanço progressivo da "mata branca" (floresta sem pinheiros) a partir das calhas dos rios formadores da bacia do rio Uruguai.

Se, por um lado, as condições em altitude são aparentemente mais adequadas ao estabelecimento dos elementos da Floresta Ombrófila Mista, por outro, em menor altitude, a entrada de elementos das florestas estacionais parece ser impulsionada por condicionantes ambientais que, embora não possam ser profundamente discutidos aqui, devem estar associados com fatores climáticos relacionados com gradientes altitudinais. Para isso, concorre a dissecação do relevo promovida pelos grandes sistemas fluviais, ocasionando o gradual rebaixamento das superfícies constituintes das bacias hidrográficas. Neste caso, é necessário admitir que os canais fluviais das grandes bacias hidrográficas teriam um papel considerável no favorecimento de rotas migratórias para as espécies entre regiões fitoecológicas distintas.

Indicativos disso foram observados pela penetração da floresta estacional para dentro dos espaços ocupados pela Floresta Ombrófila Mista através dos canais dos grandes rios nos estado do Paraná e Santa Catarina, conforme pode ser visto nos mapas publicados por Klein (1978) e Maack, (1947; 1968) e no Rio Grande do Sul (RAMBO, 1951; JARENKOW e WAECHTER, 2001). Analogamente a este processo, alguns autores citam que a Araucaria angustifolia (Bertol.) Kuntze (e provavelmente de toda a flora associada à FOM) durante o quaternário recente (a partir de $3.000 \mathrm{AP}$ ) teve sua expansão a partir de zonas mais úmidas associadas aos cursos dos rios (OLIVEIRA et al., 2005; PILLAR et al., 2009). Hoje, contudo, vários autores parecem admitir a redução da FOM frente ao avanço das florestas estacionais (Reitz; Klein 1966, Maack 1968).

Seria razoável propor, portanto, que as bacias de leste representam zonas de transição entre a FED e a FOM. Reitz e Klein (1966) discutiram sobre a expansão das florestas estacionais até uma altitude entre 500 e $700 \mathrm{~m}$, de certa forma, coincidindo com a zona de transição proposta por Torezan (2002) na bacia do rio Tibagi, a qual, segundo os autores, está compreendida no intervalo entre as cotas 500 a $800 \mathrm{~m}$, constituindo a região do médio rio Tibagi. Considerando a necessária correção latitudinal em relação ao estado do Paraná, é uma cota muito aproximada àquela considerada pelos autores acima citados para Santa Catarina. Os dados aqui apresentados indicam haver esta transição a partir da faixa dos 600 m s.n.m.

Para fundamentar ainda mais esta discussão, os $800 \mathrm{~m}$ foram considerados por Blum (2006) o limite transicional entre os tipos climáticos $\mathrm{Cfa} e$ $\mathrm{Cfb}$ na vertente oriental da Serra do Mar paranaense, o qual coincide com o ponto de transição entre a Floresta Ombrófila Densa montana e submontana. A extensão geográfica desta transição, entretanto, pode ser muito maior que a extensão de pontos amostrais analisados neste trabalho, isto porque a ausência de cobertura florestal, quando da condução 
dos trabalhos de campo, impede qualquer conjectura analítica nos extensos "vazios" florestais do estado catarinense.

\section{CONCLUSÕES}

Pode-se afirmar que os resultados das análises permitiram a observação de uma tendência de mudança estrutural da vegetação de oeste para leste. As UA alocadas nas áreas de abrangência das bacias de leste estão posicionadas em regiões mais elevadas, onde a ocorrência de geadas é mais frequente e as temperaturas médias mais baixas. Nestas UA foi possível detectar a presença de espécies características da Floresta Ombrófila Mista em meio àquelas de maior abundância, o que sugere a existência de uma região de transição, aproximadamente na faixa dos $600 \mathrm{~m}$ de altitude. Nos patamares de menor altitude, onde estão inseridas a maioria das UA contidas nas áreas das bacias do oeste, sob condições climáticas diferenciadas, a flora típica da floresta estacional decidual e semidecidual do sul do Brasil passa a figurar dentre as espécies dominantes. Propõe-se que esta constitua a área core da FED em Santa Catarina, uma vez que as espécies são típicas da área e a influência das demais fitofisionomias, principalmente da Floresta Ombrófila Mista, é pequena.

\section{AGRADECIMENTOS}

Os autores agradecem a FAPESC Fundação de Amparo à Pesquisa e Inovação do Estado de Santa Catarina pelo financiamento do projeto.

\section{REFERÊNCIAS BIBLIOGRÁFICAS}

ALBERTI, L. F.; LONGUI, S. L.; MORELATTO, L. P. Padrão fenológico de árvores e a relação com o clima. In: SCHUMACHER et al., (eds.). A Floresta Estacional Subtropical. Caracterização e ecologia no rebordo do Planalto Meridional. Santa Maria, 2011, p. 121-140.

BEHLING, H.; PILLAR, V. D.; BAUERMANN, S. G. Late Quaternary grassland (Campos), gallery forest, fire and climate dynamics, studied by pollen, charcoal and multivariate analysis of the São Francisco de Assis core in western Rio Grande do Sul (southern Brazil). Review of Palaeobotany and Palynology, Amsterdam, v. 133, n. 3-4,

\section{p. 235-248, 2005}

BEHLING, $\mathrm{H}$. Late quaternary vegetation, climate and fire history of Araucaria forest and campos region from Serra Campo Gerais Paraná state (South Brazil).Review of Paleobotany and Palinology, Amsterdam, v. 97, p. 109-121. 1997.

BEHLING, H., NEGRELLE, R. R. B. Tropical Rain Forest and Climate Dynamics of the Atlantic Lowland, Southern Brazil, during the Late Quaternary. Quaternary Research, Rotterdam, v. 56, p. 383-389, 2001.

BIGARELLA, J.J. Variações climáticas no quaternário e suas implicações no revestimento florístico do Paraná. Boletim Paranaense de Geografia, Curitiba, v. 10/15, p. 211-231, 1964.

BLUM, C. T. Floresta Ombrófila Densa na Serra da Prata, Parque Nacional Saint-Hilaire/Lange, PR - Caracterização Florística, Fitossociológica e Ambiental de um Gradiente Altitudinal. 195 f. Dissertação (Mestrado em Ciências Florestais) Universidade Federal do Paraná, Curitiba, 2006.

CIENTEC. Mata Nativa: Sistema para análise fitossociológica e elaboração de planos de manejo de florestas nativas. São Paulo, 2002, 126 p.

EPAGRI. Atlas climatológico do Estado de Santa Catarina. Disponível em $<\mathrm{http}$ ://ciram.epagri.rctsc.br>. Acesso em 20 de setembro de 2008.

FERRAZ, S. E. R.; ROBERTI, D. R. Padrões climáticos na região do extremo sul do Planalto Meridional brasileiro. In: SCHUMACHER et al., (eds.). A Floresta Estacional Subtropical. Caracterização e ecologia no rebordo do Planalto Meridional. Santa Maria, 2011, p. 09-20.

GAUCH-JUNIOR, H.G. Mulltivariate Analysis in Community Ecology. Cambridge: Cambridge University Press, 1982, 298 p.

GIEHL, E. L. H.; JARENKOW, J. A. Gradiente estrutural no componente arbóreo e relação com inundações em uma floresta ribeirinha, rio Uruguai, sul do Brasil. Acta Botanica Brasilica, Brasília, v. 22, n 3, p. 741-753. 2008

IBGE. Manual técnico da vegetação brasileira. Rio de Janeiro: IBGE, 1991, 92 p.

INOUE, M. T.; RODERJAN, C. V.; KUNIYOSHI, Y. S. Projeto Madeira do Paraná. Curitiba: FUPEF, 1984, $260 \mathrm{p}$.

JARENKOW, J.A.; WAECHTER, J. L. Composição, estrutura e relações florísticas do componente arbóreo de uma floresta estacional no Rio Grande do Sul, Brasil. Revista Brasileira de Botânica, São Paulo, v. 24, n. 3, p. 263-272, 2001.

KILCA, R. V.; LONGHI, S. L. A regeneração 
natural e a sucessão condicionada por diferentes tipos de distúrbios: um estudo de caso. In: SCHUMACHER, M. V. et al., (eds.) A Floresta Estacional Subtropical. Caracterização e ecologia no rebordo do Planalto Meridional. Santa Maria, 2011, p. 121-140.

KLEIN, R. M. Árvores nativas da floresta subtropical do Alto Uruguai. Sellowia, Itajaí, v. 24, p. 9-62, 1972.

KLEIN, R. M. Mapa Fitogeográfico do Estado de Santa Catarina. In: REITZ, R. (ed.) Flora Ilustrada Catarinense, V Parte - Mapa Fitogeográfico. Itajaí: Herbário Barbosa Rodrigues, 1978, 24 p.

KLEIN, R. M.; SLEUMER, H. O. Flacourtiáceas. In: REITZ, R. (ed.). Flora Ilustrada Catarinense. Itajaí: Herbário Barbosa Rodrigues, 1984, 96 p.

LEITE, P. F. As diferentes unidades fitoecológicas da região sul do Brasil; proposta de classificação. 168 f. Dissertação (Mestrado em Ciências Florestais) - Universidade Federal do Paraná, Curitiba, 1994.

MAACK, R. Breves notícias sobre a geologia do Paraná e Santa Catarina. Arquivos de Biologia e Tecnologia, v. 2, p. 63-154, 1947.

MAACK, R. Geografia física do Estado do Paraná. Rio de Janeiro: J. Olympio; Curitiba: Secretaria da Cultura e do Esporte do Governo do Estado do Paraná, 1968, 350 p.

MARKGRAF, F. Apocináceas. In: REITZ, R. (ed.) Flora Ilustrada Catarinense, V Parte - Mapa Fitogeográfico. Itajaí: Herbário Barbosa Rodrigues, 1968, $122 \mathrm{p}$.

MIZUSAKI, A. M. P.; THOMAZ-FILHO, A. O magmatismo pós-paleozóico no Brasil. In: MANTESSO-NETO, V. et al., (eds.). Geologia do continente sul-americano: evolução da obra de Fernando Flávio Marques de Almeida. São Paulo: Becca, 2004, p. 281-291.

OLIVEIRA, P. E. et al. Paleovegetação e paleoclima do quaternário do Brasil. In: SOUZA, C. R. et al., (eds.). Quaternário do Brasil. Ribeirão Preto: Holos. 2005, p. 52-74.

OLIVEIRA-FILHO, A. T.; FONTES, M. A. L. Patterns of floristic differentiation among Atlantic forests in southeastern Brazil and the influence of climate. Biotropica, Zurich, v. 32, n. 4B, p. 793-810. 2000.

OLIVEIRA-FILHO A. T; RATTER J. A. Vegetation physiognomies and woody flora of the cerrado biome. In: OLIVEIRA, P. S.; MARQUIS, R. J. (eds) The Cerrado of Brazil: Ecology and Natural History of a Neotropical Savanna. New York: Columbia University Press, 2002. Pp. 91-120.
PRADO, D.E.; GIBBS, P.E. Patterns of species distributions in the dry forest of South America. Annals of the Missouri Botanical Garden, St. Louis, v. 80, p. 902-927. 1993.

PEDRON, F. A.; DALMOLIN, R. S. D. Solos da região do rebordo do Planalto Meridional no Rio Grande do Sul. In: SCHUMACHER, M.V.et al.(eds.) A Floresta Estacional Subtropical. Caracterização e ecologia no rebordo do Planalto Meridional. Santa Maria, 2011, p. 33-52.

PENNINGTON, R. T.; PRADO, D. E.; PENDRY, C. A. Neotropical seasonally dry forests and Quaternary vegetation changes. Journal of Biogeography, Oxford, v. 27, n. 2, p. 261-273. 2000

PENNINGTON, R. T.; LAVIN, M.; OLIVEIRAFILHO, A. Woody Plant Diversity, Evolution, and Ecology in the Tropics: Perspectivesfrom Seasonally Dry Tropical Forests. Annual Review of Ecology, Evolution, and Systematics, Palo Alto, v. 40, p. 437-457, 2009.

PETRI, S.; FÚlFARO, V. J. Geologia do Brasil. São Paulo: EDUSP, 1983, 631 p.

PILLAR, V. D., et al., Campos sulinos: conservação e uso sustentável da biodiversidade. Brasília, MMA, 2009, 403 p.

RAMBO, B. A. Der RegenwaldamoberenUruguay. Sellowia, Itajaí, v. 7/8, p. 183-233, 1956.

RAMBO, B. A. Imigração da selva higrófila no Rio Grande do Sul. Anais Botânicos, Itajaí,v. 3, p. 5591, 1951.

REITZ, R.; KLEIN, R. M. Araucariáceas. In: Reitz, R. (ed.). Flora Ilustrada Catarinense. Itajaí: Herbário Barbosa Rodrigues, 1966. 62 p.

REITZ, P. P. Sapotáceas. In: Reitz, R. (ed.). Flora Ilustrada Catarinense. Itajaí: Herbário Barbosa Rodrigues, 1968, $72 \mathrm{p}$.

REITZ, R.; KLEIN, R. M.; REIS, A. Projeto madeira de Santa Catarina. Sellowia, Itajaí, v. 28, p. 1-320, 1978.

REITZ, R.; KLEIN, R. M.; REIS, A. Projeto madeira do Rio Grande do Sul. Sellowia, Itajaí, v. 34/35, p. 1-483, 1988.

REITZ, R. Nictagináceas. In: REITZ, R. (ed.). Flora Ilustrada Catarinense. Itajaí: Herbário Barbosa Rodrigues, 1970, $52 \mathrm{p}$.

REITZ, R. Palmeiras. In: REITZ, R. (ed.). Flora Ilustrada Catarinense. Itajaí: Herbário Barbosa Rodrigues, 1974, $189 \mathrm{p}$.

SCHUMACHER, M. V. et al., A Floresta Estacional Subtropical. Caracterização e ecologia no rebordo do Planalto Meridional. Santa Maria, 2011, $320 \mathrm{p}$. 
SCIPIONI, M. C. et al..Análise dos padrões florísticos e estruturais de uma comunidade arbóreo-arbustiva em um gradiente de solo e relevo. In: SCHUMACHER, M. V. et al., (eds.) A Floresta Estacional Subtropical. Caracterização e ecologia no rebordo do Planalto Meridional. Santa Maria, 2011, p. 85-104.

SMITH, L. B. Boragináceas. In: REITZ, R. (ed.) Flora Ilustrada Catarinense. Itajaí: Herbário Barbosa, 1970, $85 \mathrm{p}$.

SPICHIGER, R.; CALENGE, C.; BISE, B. Geographical zonation in the Neotropics of tree species characteristics of the Paraguay-Paraná Basin. Journal of Biogeography, Oxford,v. 31, p. 1489-1501. 2004

TER BRAAK, C. J. F.;SMILAUER, P. CANOCO reference manual and CanoDraw for Windows user's guide: software for canonical community ordination (version 4.5). Microcomputer Power, Ithaca, New York, 2002, $500 \mathrm{p}$.

TOREZAN, J. M. Nota sobre a vegetação da bacia do rio Tibagi. In: MEDRI, M. et al., (eds.) A bacia do rio Tibagi. Londrina, 2002, p. 103-124.

VELOSO, H. P.;KLEIN, R. M. As comunidades e associações vegetais da Mata Pluvial do Sul do Brasil. II. Dinamismo e fidelidade das espécies em associações do Município de Brusque, Estado de SC. Sellowia, v. 10, p 9-124. 1959.

VELOSO, H. P.; RANGEL FILHO, A. L. R.; LIMA, J. C. A. Classificação da vegetação brasileira, adaptada a um sistema universal. Rio de Janeiro: IBGE, Departamento de Recursos Naturais e Estudos Ambientais. 1991. 123 p.

VIBRANS, A. C. et al.Inventário florístico florestal de Santa Catarina (IFFSC): aspectos metodológicos e operacionais. Pesquisa Florestal Brasileira, Colombo, v. 30, n. 64, p. 291-302, 2010.

VIBRANS, A. C.et al.Structure of Mixed Ombrophyllous Forests with Araucaria angustifolia (Araucariaceae) under external stress in southern Brazil.Revista de Biologia Tropical, San José, v. 59, n. 3, p. 1371-1387, 2011. 